\title{
Papers
}

\section{Dietary fat intake and prevention of cardiovascular disease: systematic review}

\author{
Lee Hooper, Carolyn D Summerbell, Julian P T Higgins, Rachel L Thompson, Nigel E Capps, \\ George Davey Smith, Rudolph A Riemersma, Shah Ebrahim
}

\begin{abstract}
Objective To assess the effect of reduction or modification of dietary fat intake on total and cardiovascular mortality and cardiovascular morbidity. Design Systematic review.

Data sources Cochrane Library, Medline, Embase, CAB abstracts, SIGLE, CVRCT registry, and biographies were searched; trials known to experts were included.

Included studies Randomised controlled trials stating intention to reduce or modify fat or cholesterol intake in healthy adult participants over at least six months. Inclusion decisions, validity, and data extraction were duplicated. Meta-analysis (random effects methodology), meta-regression, and funnel plots were performed.

Results 27 studies (30 902 person years of observation) were included. Alteration of dietary fat intake had small effects on total mortality (rate ratio $0.98 ; 95 \%$ confidence interval 0.86 to 1.12 ).

Cardiovascular mortality was reduced by $9 \%(0.91$; 0.77 to 1.07$)$ and cardiovascular events by $16 \%(0.84$; 0.72 to 0.99$)$, which was attenuated $(0.86 ; 0.72$ to 1.03$)$ in a sensitivity analysis that excluded a trial using oily fish. Trials with at least two years' follow up provided stronger evidence of protection from cardiovascular events $(0.76 ; 0.65$ to 0.90$)$.

Conclusions There is a small but potentially important reduction in cardiovascular risk with reduction or modification of dietary fat intake, seen particularly in trials of longer duration.

\section{Introduction}

For half a century the relation between dietary fat and cardiovascular disease, the "diet-heart" hypothesis, has been a central tenet of strategies for risk reduction in individuals and populations. ${ }^{1}$ Observational studies ${ }^{2}$ and systematic reviews of clinical trials with risk factors as end points ${ }^{3-7}$ support this relation. However, evidence of a beneficial effect in observational studies does not provide convincing evidence. For example, the protective effect of $\beta$ carotene in coronary heart disease was strongly supported by observational evidence, but large randomised controlled trials showed no protective effects on morbidity or mortality.
\end{abstract}

Previous investigators have extrapolated the reduction in coronary heart disease that might be expected from changes in blood cholesterol concentration, ${ }^{47}$ even though there is direct evidence from randomised controlled trials of the effect of modification or reduction of intake of dietary fats. We therefore performed a systematic review to assess the effect of change in dietary fat intake, which would be expected to result in a lowering of cholesterol concentration, on mortality and cardiovascular morbidity, using all available randomised clinical trials. The interventions included any of the following: reduction in intake of total fat; reduction in intake of saturated fat; reduction in intake of dietary cholesterol; or a shift from saturated to unsaturated fat.

\section{Methods}

Much of the methodology has been reported previously. ${ }^{9}$ Briefly, we developed a search strategy to search for nutrition based randomised controlled trials on the Cochrane Library, Medline, Embase, CAB abstracts, CVRCT registry (inception of database to mid-1998), and SIGLE (January 1999). We searched bibliographies and contacted related Cochrane Review Groups and 60 experts (May 1999) for further trials. There were no language restrictions.

The inclusion criteria were adequate randomisation; usual or control diet or placebo group; stated aim of intervention was reduction or modification of intake of dietary fat or cholesterol, unless the intervention was exclusively omega 3 fatty acids; intervention was not multifactorial; the intervention group were not children, acutely ill, or pregnant; the intervention (diet provided or supplementation) continued for at least six months or follow up (after dietary advice) was at least six months; and data on mortality or cardiovascular morbidity were available.

Our primary outcomes of interest were effects of intervention on total mortality, cardiovascular mortality, combined cardiovascular events (including all available data on cardiovascular deaths, non-fatal myocardial infarction, stroke, angina, heart failure, peripheral vascular disease, angioplasty, and coronary artery bypass grafting), and quality of life. Event data were included only when they occurred during provision of diet or supplement (when these were provided) or

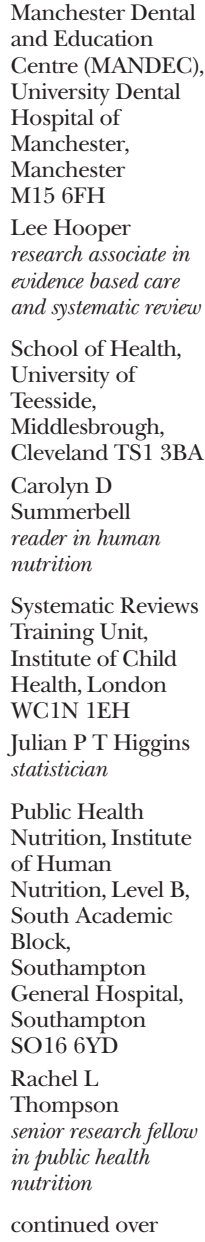

Manchester Dental and Education Centre (MANDEC), University Dental Hospital of Manchester, Manchester M15 6FH

Lee Hooper research associate in evidence based care and systematic review

School of Health,

University of

Teesside,

Middlesbrough,

Cleveland TS1 3BA

Carolyn D

Summerbell reader in human nutrition

Systematic Reviews Training Unit, Institute of Child

Health, London

WC1N 1EH

Julian P T Higgins

statistician

Public Health

Nutrition, Institute

of Human

Nutrition, Level B,

South Academic

Block,

Southampton

General Hospital,

Southampton

SO16 6YD

Rachel L

Thompson senior research fellow

in public health

nutrition

continued over

BMJ 2001;322:757-63

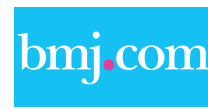

A table giving details of included studies is available on the BMJ's

website 
Department of Clinical

Biochemistry,

Princess Royal

Hospital NHS

Trust, Apley Castle

Telford TF6 6TF

Nigel E Capps

consultant chemical

pathologist for

Shropshire

Department of

Social Medicine,

University of

Bristol, Canynge

Hall, Bristol

BS8 2PR

George Davey

Smith

professor of clinical

epidemiology

Shah Ebrahim

professor in

epidemiology of

ageing

Cardiovascular

Research, University

of Edinburgh.

Edinburgh

EH8 9XF

Rudolph A

Riemersma

senior lecturer in

cardiac biochemistry

Correspondence to:

L Hooper

lee.hooper@

man.ac.uk while randomisation and blinding were maintained (in dietary advice trials).

Inclusion was assessed independently by two assessors (LH, RLT) and differences were resolved by discussion, with, if necessary, a third reviewer (RAR). Data extracted independently in duplicate (by LH and RLT) included type of participants, interventions, and outcomes; characteristics of trial quality; numbers of events; total patient years in trial; and data on potential effect modifiers. Effect modifiers included participants' baseline risk of cardiovascular disease, trial duration, mode of intervention, change in intake of dietary fats, and serum cholesterol concentration achieved.

Criteria for assessment of trial quality included method of randomisation, physician blinding, participant blinding, and any systematic difference in care between the intervention groups.

We used meta-analysis to explore the primary hypothesis, which was that reduction or modification of dietary fat intake affects mortality, cardiovascular mortality, and cardiovascular events. We examined the effects of duration of intervention, initial level of cardiovascular risk and dietary fat intake, type of intervention, and changes in intake of total, saturated, monounsaturated, and polyunsaturated fats and blood cholesterol concentration using subgrouping of trials and meta-regression. We excluded trials that aimed to alter omega 3 intake as the method of action (if any) is probably different from any action caused by the reduction in intake of total or saturated fat-that is, it does not primarily lower low density lipoprotein cholesterol.

Treatment effect was measured as a rate ratio and meta-analysis performed as a weighted average of log rate ratios. ${ }^{10}$ The meta-analysis used random effects methodology ${ }^{11}$ within S-PLUS. ${ }^{12}$ Meta-analysis pools results of individual trials, with weighting so that results with higher precision (related to sample size) contribute more to the combined outcome. We used the STATA command metareg ${ }^{13}$ for random effects meta-regression. ${ }^{14}$ Meta-regression investigates the effect of one or more study characteristics on the size of treatment effect, taking precision into account. A genuine relation may be inferred (for example, if the extent of reduction in total fat achieved by the intervention is associated with the degree of reduction in mortality) when a slope is significantly different from zero. We used funnel plot asymmetry to detect any bias in the trials retrieved. ${ }^{15}$

\section{Results}

\section{Study characteristics}

We identified 27 studies, comprising 40 distinct intervention arms over 30902 person years of observation. ${ }^{16-42}$ A table with details of all 27 studies can be found on the $B M J$ 's website. Figure 1 gives a flow chart of studies assessed and excluded at various stages of the review. Table 1 gives details of extracted data. We found almost no data on quality of life or levels of trans fats. The $\kappa$ statistic for inter-rater agreement on inclusion or exclusion of potential trials was $0.61 .^{43}$

Reduction or modification of dietary fat intake

The pooled rate ratio for total mortality was 0.98 (95\% confidence interval 0.86 to 1.12 ), which indicates little,

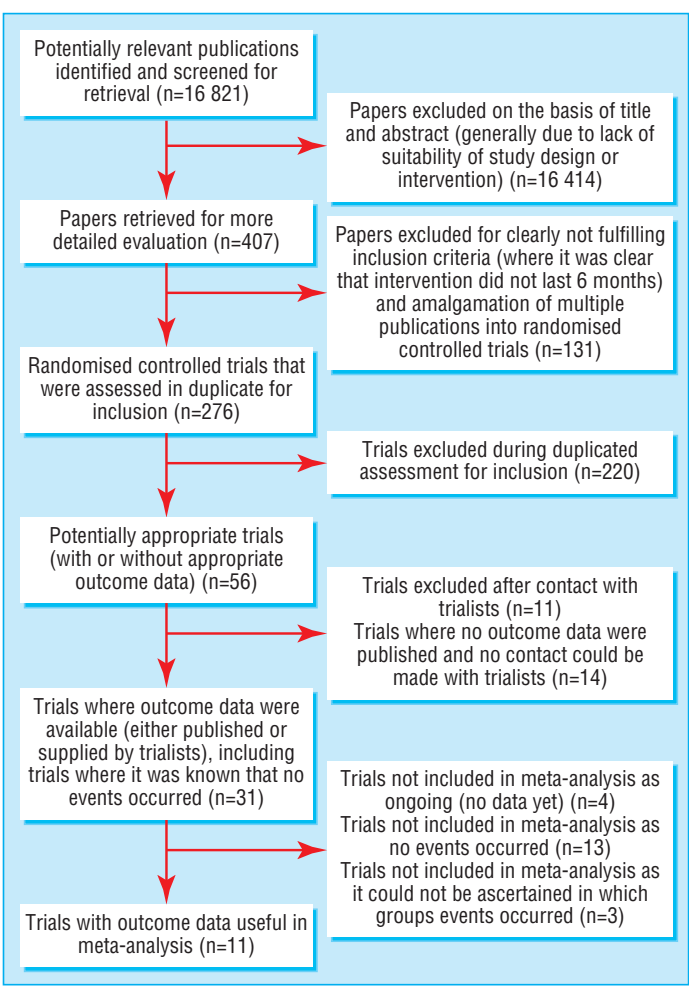

Fig 1 Summary of systematic review profile

if any, effect (fig 2). The data on cardiovascular mortality indicate a slight $(9 \%)$ protection from modification of intake of dietary fat $(0.91 ; 0.77$ to 1.07$)$ (fig 3 ) and a $16 \%$ reduction in cardiovascular events $(0.84$; 0.72 to 0.99 ) (fig 4). A funnel plot of effect size versus sample size did not show any evidence of bias (data not shown).

The Oslo diet-heart trial provided some oily fish (a source of omega 3 fatty acids) to participants in the intervention group. ${ }^{33}$ Exclusion of the results of this trial attenuated the rate ratios for all three main outcomes (total mortality 1.02 (0.91 to 1.14 ); cardiovascular mortality 0.94 (0.79 to 1.11$)$; combined cardiovascular events 0.86 (0.72 to 1.03$)$ ).

Figure 5 shows the results of the meta-analyses, subgroupings, and sensitivity analyses performed. Table 2 shows the results of the meta-regressions.

\section{Duration of follow up, initial level of cardiovascular risk, type of intervention, and dietary fat intake at baseline}

We obtained results for specific length of time on diet, initial level of cardiovascular risk, or mode of intervention through subgrouping of trials. Trials in which the mean length of follow up exceeded two years showed somewhat larger reductions in combined cardiovascular events $(0.76$ (0.65 to 0.90$) v 0.96$ ( 0.75 to 1.23 ) than trials of less than two years' duration). When we excluded data from the Oslo diet-heart study, the rate ratio for combined cardiovascular events for trials with mean follow up longer than two years was not altered $(0.77 ; 0.62$ to 0.96$)$. Total mortality was not substantially influenced by mean follow up.

The relation between mean follow up and cardiovascular events was further explored through meta-regression. The negative slope (ln (rate ratio) $v$ 
Table 1 Outcome data from included trials of diet and health for control/intervention groups

\begin{tabular}{|c|c|c|c|c|c|}
\hline Included trial arm & $\begin{array}{l}\text { Person years of } \\
\text { observation }\end{array}$ & Total mortality & CVD mortality & Combined CVD events & Events included in combined CVD events \\
\hline BDIT pilot studies ${ }^{16}$ & $1138 / 986$ & $3 \dagger$ & - & - & - \\
\hline Diet and reinfarction (DART) $)^{17}$ & $1917 / 1925$ & $113 / 111$ & $100 / 101$ & $147 / 136$ & CV deaths (including stroke) plus non-fatal MI \\
\hline Diet and gallstones ${ }^{18}$ & $10 / 11$ & 0 & - & - & - \\
\hline German fat reduced ${ }^{19}$ & $25 / 26$ & 0 & 0 & 0 & CV deaths, non-fatal MI, stroke \\
\hline Glasgow diet in hypertension ${ }^{20}$ & $34 / 33$ & 0 & 0 & 0 & CV deaths \\
\hline Glasgow weight loss ${ }^{21}$ & $22 / 24$ & 0 & 0 & 0 & CV deaths, non-fatal MI, stroke \\
\hline Kentucky low fat ${ }^{22}$ & $56 / 105$ & 0 & 0 & 0 & CV deaths, fatal and non-fatal MI, stroke \\
\hline \multicolumn{6}{|l|}{ Kuopio } \\
\hline $\begin{array}{l}\text { Fat modified (American Heart } \\
\text { Association) }\end{array}$ & $6 / 20$ & 0 & - & - & - \\
\hline Fat modified (low fat) & $6 / 20$ & 0 & - & - & - \\
\hline Fat modified (mono) & $6 / 20$ & 0 & - & - & - \\
\hline Linoleic enrichment ${ }^{24}$ & $40 / 34$ & 0 & 0 & 0 & CV deaths, non-fatal MI, stroke \\
\hline \multicolumn{6}{|l|}{ London corn/olive ${ }^{25}$ : } \\
\hline Corn & $22 / 41$ & $0.5 / 5$ & $0.5 / 5$ & $5.5 / 15$ & CV deaths, non-fatal MI, angina, stroke \\
\hline London low fat ${ }^{26}$ & $393 / 374$ & $24 / 20$ & $20 / 17$ & $42 / 38$ & CV deaths, non-fatal MI \\
\hline Low fat in breast cancer ${ }^{27}$ & $171 / 170$ & At least $2 \dagger$ & & & \\
\hline Mastopathy $\operatorname{diet}^{28}$ & $4 / 5$ & 0 & 0 & 0 & CV deaths \\
\hline Minnesota coronary ${ }^{29}$ & $4715 / 4823$ & $248 / 269$ & $157 / 157$ & $129 / 134$ & Total MI, sudden death, stroke \\
\hline MRC soya ${ }^{30}$ & $715 / 751$ & $31 / 28$ & $25 / 27$ & $74 / 62$ & CV deaths, total MI \\
\hline $\begin{array}{l}\text { Multicentre study on fat reduction } \\
\text { (MSFAT) })^{31}\end{array}$ & $56 / 59$ & 0 & - & - & - \\
\hline \multicolumn{6}{|l|}{ National diet-heart study ${ }^{32}$ : } \\
\hline Faribault 1st, B & $18 / 52$ & - & 0 & 0 & Total Ml, peripheral vascular events \\
\hline Faribault 1st, C & $18 / 49$ & - & 0 & 0 & Total MI, peripheral vascular events \\
\hline Faribault 1st, E & $18 / 53$ & - & 0 & 0 & Total MI, peripheral vascular events \\
\hline Open 1st, B & $120 / 358$ & - & 0 & $0.3 / 0$ & Total MI, peripheral vascular events \\
\hline Open 1st, C & $120 / 361$ & - & 0 & $0.3 / 4$ & Total MI, peripheral vascular events \\
\hline Open 1st, $X$ & $120 / 50$ & - & 0 & $0.3 / 1$ & Total MI, peripheral vascular events \\
\hline Open 2nd, BC & $59 / 112$ & - & 0 & $1.3 / 0$ & Total MI, peripheral vascular events \\
\hline Open 2nd, F & $59 / 74$ & - & 0 & $1.3 / 1$ & Total MI, peripheral vascular events \\
\hline Oslo diet-heart ${ }^{33}$ & $885 / 895$ & $65 / 48$ & $52 / 38$ & $91 / 66$ & Total MI, sudden death, stroke, angina \\
\hline 0xford retinopathy ${ }^{34}$ & $1160 / 1160$ & $34 \dagger$ & - & - & - \\
\hline Sollentuna diet ${ }^{35}$ & $19 / 20$ & 0 & 0 & 0 & Total MI, CV deaths, stroke \\
\hline Stanford weight ${ }^{36}$ & $42 / 42$ & 0 & 0 & 0 & CV deaths \\
\hline $\begin{array}{l}\text { St Thomas' atherosclerosis regression } \\
\text { (STARS) }^{37}\end{array}$ & $88 / 91$ & $3 / 1$ & $3 / 1$ & $20 / 8$ & $\begin{array}{l}\text { CV deaths, non-fatal MI, angina, stroke, CABG, } \\
\text { angioplasty }\end{array}$ \\
\hline Sydney diet-heart ${ }^{38}$ & $1011 / 939$ & $28 / 39$ & - & - & ( \\
\hline Toronto polyp prevention ${ }^{39}$ & $204 / 198$ & 0 & 0 & 0 & CV deaths \\
\hline \multicolumn{6}{|l|}{ Turku weight ${ }^{40}$ : } \\
\hline Mixed & $21 / 41$ & 0 & 0 & 0 & $\begin{array}{l}\text { CV deaths, non-fatal MI, angina, stroke, heart failure, } \\
\text { angioplasty, CABG }\end{array}$ \\
\hline Vegetarian & $21 / 38$ & 0 & 0 & 0 & $\begin{array}{l}\text { CV deaths, non-fatal MI, angina, stroke, heart failure, } \\
\text { angioplasty, CABG }\end{array}$ \\
\hline Veterans administration ${ }^{41}$ & $1544 / 1588$ & $177 / 174$ & $59 / 44$ & $122 / 97$ & $\begin{array}{l}\text { Sudden death, definite Ml, definite stroke, angina, } \\
\text { peripheral vascular events }\end{array}$ \\
\hline Veterans diet and skin cancer ${ }^{42}$ & $125 / 123$ & $2 / 1$ & $2 / 0$ & $2 / 0$ & CV deaths \\
\hline Total, all trials & 15096/15806 (30 902) & 692/699 (1430) & $419 / 393(812)$ & $643 / 573(1216)$ & - \\
\hline Total, high risk participants & $5053 / 5054$ (10 107) & $265 / 255(520)$ & 201/192 (393) & $385 / 336(721)$ & - \\
\hline
\end{tabular}

$\mathrm{CVD}=$ cardiovascular disease, $\mathrm{CV}=$ cardiovascular, $\mathrm{MI}=$ myocardial infarction, $\mathrm{CABG}=$ coronary artery bypass grafting.

*Events counted only once, only major event counted for each participant.

†Deaths occurred but it was not clear in which group.

mean follow up time, slope $-0.096 ;-0.190$ to -0.002 ) suggests fewer cardiovascular events at longer mean follow up times in the groups with reduced or modified fat intake.

Trials with participants at high initial cardiovascular risk suggested very similar levels of protection from combined cardiovascular events (rate ratio 0.84; 0.70 to 0.99$)$ as did trials with participants at low cardiovascular risk $(0.82 ; 0.56$ to 1.20$)$. Neither the method of dietary modification (by diet advice, advice plus a supplement, or diet provided) nor the initial level of intake of dietary fat influenced rate ratios.
Changes in fat intake and blood cholesterol

\section{concentration}

We used meta-regression to explore the effects on total mortality and combined cardiovascular events of changing the proportion of energy from total fat and of altering serum cholesterol concentrations. Meta-regressions also explored the relation between change in proportion of saturated fat, polyunsaturated fat, and monounsaturated fat on cardiovascular events. These suggested that total mortality and cardiovascular events were reduced as energy from fat, and as serum cholesterol concentrations, fell. Similarly, cardiovascular 


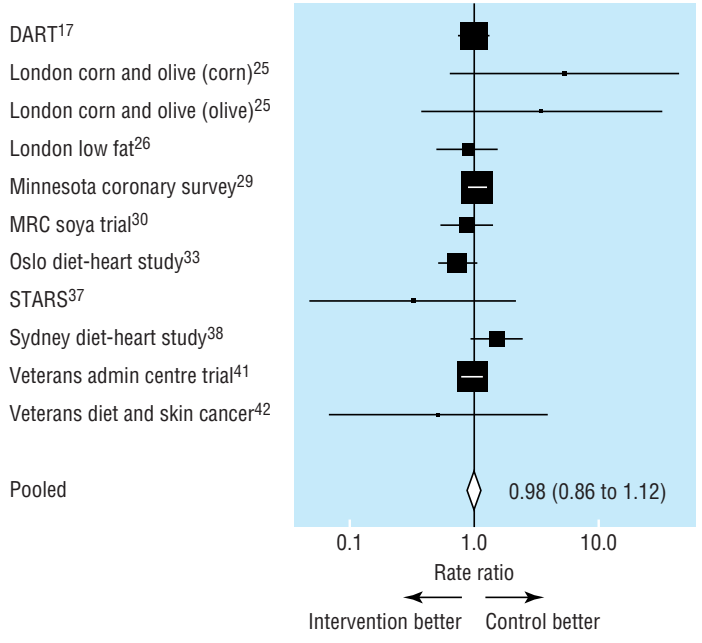

Fig 2 Estimates of total mortality (95\% confidence intervals) from meta-analysis

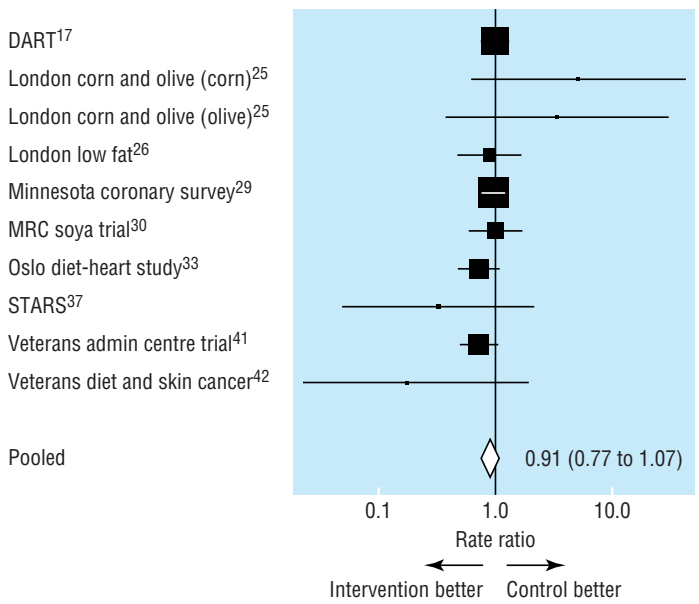

Fig 3 Estimates of cardiovascular mortality (95\% confidence intervals) from meta-analysis

events were reduced as each of the fat subfractions decreased. However, none of these relations were convincing (none of the slopes were different from zero at a $\mathrm{P}<0.05$, see table 2), except for that of monounsaturated fat. Here the slope depended heavily on one medium sized trial, St Thomas's atherosclerosis regression study (STARS), ${ }^{37}$ and should therefore be treated with caution.

\section{Discussion}

Pooled results of dietary fat trials indicate that reduction or modification of intake of dietary fat reduces the incidence of combined cardiovascular events by $16 \%$ (rate ratio $0.84 ; 95 \%$ confidence interval 0.72 to 0.99$)$ and cardiovascular deaths by $9 \%(0.91$; 0.77 to 1.07$)$. No effect was seen on total mortality.

Exclusion of data from the Oslo diet study ${ }^{33}$ attenuated the effects on cardiovascular events. In this trial participants in the intervention group were supplied with oily fish, in addition to dietary advice. Oily fish, which is rich in omega 3 fatty acids, seems to have independent beneficial effects, ${ }^{44}$ so the benefits seen in this trial may have been due to the fish oils and not to cholesterol lowering or alterations in other dietary fats.

\section{Duration of trial effect}

Subgrouping by length of mean follow up suggests that virtually all protection from cardiovascular events occurs in trials of at least two years' duration. In trials with mean follow up of two years or less the reduction in events was only $4 \%$, whereas in trials with longer follow up reductions of up to $24 \%$ were seen. This effect was confirmed in a meta-regression.

The division at two years was chosen after we studied initial data from the Scandinavian simvastatin survival study (4S), which assessed the effect of simvastatin on mortality and morbidity after myocardial infarction. ${ }^{45}$ In that study little difference in event rates between treated and control groups emerged until after two years. The similar time lag between the effects of dietary intervention and statins suggests a common mechanism, perhaps through effects on the scale, type, and stability of atherosclerotic plaques (rather than rapid alteration in blood coagulability), but other mechanisms may also be operating.

It is not clear whether it is the duration of the intervention or the duration of the follow up that determines whether the intervention is effective. Sustained change in dietary behaviour, promoted by long interventions, is probably necessary to achieve reduction in cardiovascular events, and lengthy follow up is probably required before pathophysiological changes that reduce clinical events are observed.

\section{Initial level of cardiovascular risk}

Subgrouping suggested no effect of initial level of risk on outcomes. Both high and low risk groups had a similar level of risk reduction for combined cardiovascular events. This is in contrast to results of previous studies ${ }^{46}$ though initial levels of risk in studies in this systematic review were generally high (people in control group at "low risk" of cardiovascular events suffered 2.57 events per 100 people per year and those at "high risk" 7.62 events per 100 people per year).

Most of the events in this review occurred in men. Only two trials with events included women ${ }^{29} 42$ so it may not be appropriate to generalise these results to women.

\section{Type of intervention}

Subgrouping by mode of intervention showed no benefit of providing the entire diet compared with dietary advice or advice and a supplement. This was surprising as we expected that provision of food would have a more powerful effect on events than dietary advice alone.

\section{Changes in blood cholesterol concentration}

Meta-regression provided weak evidence that a greater reduction in serum cholesterol concentrations in the intervention group compared with the control group resulted in a slightly greater reduction in cardiovascular events and mortality.

A reduction of over $20 \%$ in total serum cholesterol concentration can result in a $25 \%$ fall in mortality from coronary heart disease. ${ }^{47}$ Within dietary trials in this review the mean initial serum cholesterol concentration was $5.8 \mathrm{mmol} / \mathrm{l}$, with a fall of $0.64 \mathrm{mmol} / \mathrm{l}(11 \%)$. This degree of reduction is similar to that achieved by 
early fibrates, which show reductions in rates of coronary heart disease only among those at high risk. ${ }^{46}$ However, early fibrates seemed to increase mortality from other causes, and hence any benefit from this reduction in cholesterol concentration was outweighed by adverse effects of the drugs themselves. In dietary modification this degree of cholesterol lowering is probably of modest overall benefit.

\section{Methodology of the review}

In this review we aimed to find trials that modified or reduced dietary fat intake for at least six months, even when mortality and morbidity were not reported. We tried to contact trial authors to ascertain whether it was known if any deaths or cardiovascular events had occurred. For this reason, many of the included trials are small but are included in the hope of augmenting the data from larger trials and reducing bias. Although small trials cannot individually hope to achieve useful data on rare events, in meta-analysis we are increasing the power of the group of studies by pooling.

We included factorial trials (for example, the diet and reinfarction trial (DART) ${ }^{17}$ ) when it was possible to separate out the data on the effect of change in dietary fat from the other interventions (which are randomly distributed across the fat control and intervention groups). We excluded multiple risk factor intervention trials as it is not possible to disaggregate the effects of change in dietary fat intake from other, potentially effective interventions such as increasing exercise, stopping smoking, and change in other dietary constituents. There is already a systematic review on this topic. ${ }^{48}$ We excluded the Lyon heart study ${ }^{49}$ as inclusion in our review was decided by the stated intention of the trial. ${ }^{49}$ This trial nowhere states the intention to reduce or modify dietary fat intake and the major effect on diet was to increase the omega 3 fat intake. We excluded the Finnish mental hospital study ${ }^{50}$ as it was not a truly randomised design (a cluster randomised trial with only two clusters).

Although we amassed 30902 person years of observation, 1430 deaths, and 1216 cardiovascular events, considerable uncertainty exists over the size of effects and the means by which they were achieved given the scarcity of trials longer than two years' duration. It is unlikely that further resources will now be forthcoming to perform a large trial of dietary modification. Consequently the evidence pooled in this review contributes all that is available to guide clinical practice and health policy on dietary manipulation. However, publication of data on deaths or cardio-

Table 2 Effect of modification of dietary fat intake and serum cholesterol concentration on mortality and cardiovascular outcomes, results of meta-regressions performed

\begin{tabular}{ll}
\hline Outcome measure and test variable & Slope $\mathbf{( 9 5 \% ~} \mathbf{C l})$ \\
\hline Mortality $^{*}$ & \\
\hline Total fat & $0.15(-0.009$ to 0.039$)$ \\
\hline Serum cholesterol & $0.297(-0.141$ to 0.734$)$ \\
\hline Cardiovascular events & \\
\hline Total fat & $0.004(-0.012$ to 0.021$)$ \\
\hline Saturated fat & $0.009(-0.047$ to 0.064$)$ \\
\hline Polyunsaturated fat & $0.014(-0.034$ to 0.061$)$ \\
\hline Monounsaturated fat & $0.167(0.046$ to 0.288$)$ \\
\hline Serum cholesterol & $0.296(-0.094$ to 0.687$)$ \\
\hline${ }^{*}$ In (rate ratio). &
\end{tabular}

DART $^{17}$

London corn and olive (corn) ${ }^{25}$ London corn and olive (olive) ${ }^{25}$ London low fat 26

Minnesota coronary survey 29 MRC soya tria|30

National diet-heart $(0 \text { 1st B })^{32}$ National diet-heart $(0$ 1st C C) National diet-heart $(0 \text { 1st } X)^{32}$ National diet-heart $(0 \text { 2nd BC })^{32}$ National diet-heart $(0 \text { 2nd F })^{32}$ National diet-heart $(0 \text { 2nd } G)^{32}$ Oslo diet-heart study ${ }^{33}$ STARS $^{37}$

Veterans admin centre trial 41 Veterans diet and skin cancer ${ }^{42}$ Pooled

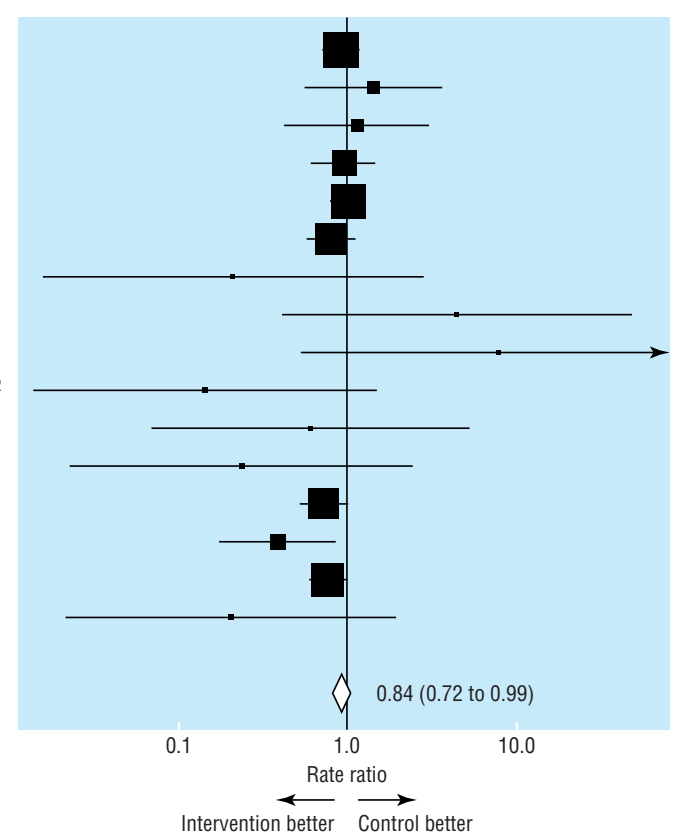

Fig 4 Estimates of combined cardiovascular events (95\% confidence intervals) from meta-analysis

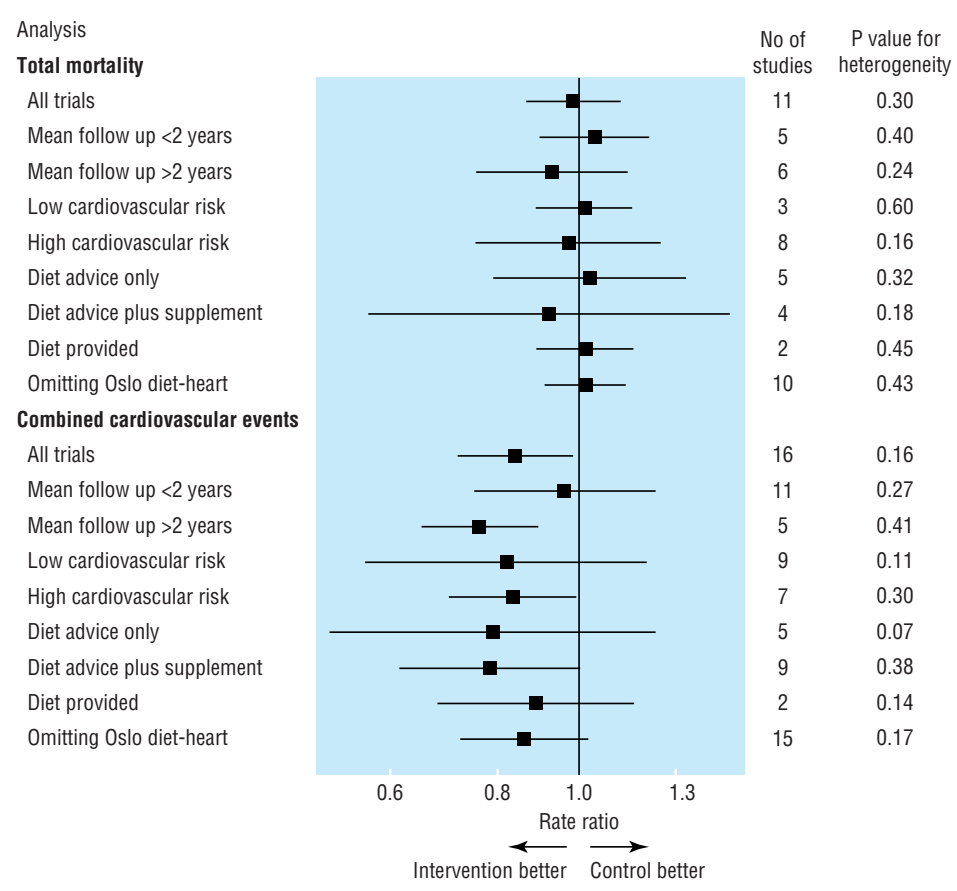

Fig 5 Total mortality and combined cardiovascular events (95\% confidence intervals) from subgroup and sensitivity analyses within meta-analyses

vascular events in the large ongoing trials of dietary fat lowering with cancer end points would augment currently available data.

\section{Conclusions}

In this review we have tried to separate out whether changes in individual fatty acid fractions are responsible for any benefits to health (using the technique of meta-regression). The answers are not definitive, the data being too sparse to be convincing. We are left with 


\section{What is already known on this topic}

The epidemiological relation between dietary fat intake and cardiovascular disease is central in strategies aimed at risk reduction in populations and individuals

Systematic review of randomised controlled trials supports manipulation of dietary fat to control serum lipid concentrations, though evidence of effect on one risk factor does not rule out an opposite or reinforced effect on another unstudied risk factor

Randomised controlled trials of dietary fat reduction or modification have shown varying results on cardiovascular morbidity and mortality

\section{What this study adds}

Systematic review of trials of modified fat intake shows that reduction or modification of dietary fat intake results in reductions in cardiovascular events, but only in trials of at least two years' duration

There is little effect on total mortality

Despite decades of effort and many thousands of people randomised, there is still only limited and inconclusive evidence of the effects of modification of total, saturated, monounsaturated, or polyunsaturated fats on cardiovascular morbidity and mortality

a suggestion that less total fat or less of any individual fatty acid fraction in the diet is beneficial.

The findings on cardiovascular events are broadly in keeping with benefits that might be expected from modest lowering of cholesterol concentration and certainly provide support, at an individual level, for the central role of dietary fat intake in the causation of cardiovascular disease.

This study was conducted as a Cochrane systematic review under the auspices of the Cochrane Heart Group, whose assistance is gratefully acknowledged. We thank Gill Clements for her comments throughout the review, all those at the Systematic Reviews Training Unit for their help and support, and all the trialists and experts who kindly provided information and advice. The original version of this review is available in the Cochrane Library (Hooper L, Summerbell CD, Higgins JPT, Thompson RL, Clements G, Capps N, et al. Reduced or modified dietary fat for prevention of cardiovascular disease. Cochrane Database Syst Rev 2000;(2):CD002137) but does not include some post-hoc analysis performed as a result of $B M J$ reviewer's comments.

Contributors: All authors were actively involved in the design of the review and provision of critical revisions to the manuscript. JPTH performed the statistical analyses, RLT duplicated trial inclusion/exclusion and data extraction, and RAR arbitrated on study inclusion when necessary. SE and CDS were primary advisers. GDS provided epidemiological expertise and NEC provided a clinical perspective. LH originated and was primarily responsible for planning and carrying out the review, was the principal author, and is guarantor for the paper.

Funding: LH's work on this review was partly funded by a studentship from the Systematic Reviews Training Unit, Institute of Child Health, University of London, and Shropshire Health Authority, Shrewsbury, contributed to travel expenses. RAR is supported by the British Heart Foundation.

Competing interests: None declared.

1 Morrison LM, Awierlein M, Wolfson E. The effects of low fat low cholesterol diets on the serum lipids. Circulation 1950:2:475-6.

2 Hu FB, Stampfer MJ, Manson JE, Rimm EB, Colditz GA, Rosner BA, et al. Dietary fat intake and the risk of coronary heart disease in women. $N$ Engl J Med 1997;337:1491-9.

3 Yu-Poth S, Zhao G, Etherton T, Naglak M, Jonnalagadda SS, Kris-Etherton PM. Effects of the national cholesterol education program's step I and step II dietary intervention programs on cardiovascular disease risk factors: a meta-analysis. Am J Clin Nutr 1999;69:632-46.
4 Tang JL, Armitage JM, Lancaster T, Silagy CA, Fowler GH, Neil HAW Systematic review of dietary intervention trials to lower blood cholesterol in free-living subjects. BMJ 1998;316:1213-20.

5 Brunner E, White I, Thorogood M, Bristow A, Curle D, Marmot M. Can dietary interventions change diet and cardiovascular risk factors? A meta-analysis of randomized controlled trials. Am J Public Health 1997:87:1415-22.

6 Clarke R, Frost C, Collins R, Appleby P, Peto R. Dietary lipids and blood cholesterol: quantitative meta-analysis of metabolic ward studies. BMJ 1997;314:112-7

7 Mensink RP, Katan MB. Effect of dietary fatty acids on serum lipids and lipoproteins. A meta-analysis of 27 trials. Arterioscler Thromb 1992;12:911-9.

8 Egger M, Schneider M, Davey Smith G. Spurious precision? Meta-analysis of observational studies. BMJ 1998;316:140-4

9 Hooper L, Summerbell CD, Higgins JPT, Thompson RL, Clements G, Capps N, et al. Reduced or modified dietary fat for prevention of cardiovascular disease. Cochrane Database Syst Rev 2000;(2):CD002137.

10 Hasselblad V, McCrory DC. Meta-analytic tools for medical decision making: a practical guide. Med Decis Making 1995;15:81-96.

11 DerSimonian R, Laird N. Meta-analysis in clinical trials. Control Clin Trials 1986;7:177-88.

12 Higgins JPT. Ciplot:confidence interval plots using S-PLUS. Manual version 2. London: Institute of Child Health, 1999

13 Sharp S. Meta-analysis regression. Stats Tech Bull 1998;42:16-22.

14 Berkley CS, Hoaglin DC, Mosteller F, Colditz GA. A random-effects regression model for meta-analysis. Stat Med 1995;14:395-411.

15 Egger M, Davey Smith G, Schneider M, Minder C. Bias in meta-analysis detected by a simple, graphical test. BMJ 1997;315:629-34.

16 Boyd NF, Martin LJ, Beaton M, Cousins M, Kriukov V. Long-term effects of participation in a randomized trial of a low-fat, high-carbohydrate diet. Cancer Epidemiol Biomarkers Prev 1996;5:217-22.

17 Burr ML, Fehily AM, Gilbert JF, Rogers S, Holliday RM, Sweetnam PM, et al. Effects of changes in fat, fish, and fibre intakes on death and myocardia reinfarction: diet and reinfarction trial (DART). Lancet 1989;2:757-61.

18 Frenkiel PG, Lee DW, Cohen H, Gilmore CJ, Resser K, Bonorris GG, et al The effect of diet on bile acid kinetics and biliary lipid secretion in gallstone patients treated with ursodeoxycholic acid. Am J Clin Nutr $1986 ; 43: 239-50$

19 Seppelt B, Weststrate JA, Reinert A, Johnson D, Luder W, Zunft H] Langzeiteffekte einer Ernahrung mit fettreduzierten Lebensmitteln auf die Energieaufnahme und das Korpergewicht [Long term effects of nutrition with fat-reduced foods on energy consumption and body weight]. Z Ernahrungswiss 1996;35:369-77.

20 Curzio JL, Kennedy SS, Elliott HL, Farish E, Barnes JF, Howie CA, et al. Hypercholesterolaemia in treated hypertensives: a controlled trial of intensive dietary advice. J Hypertens Suppl 1989;7:S254-55.

21 Lean MEJ, Han TS, Prvan T, Richmond PR, Avenell A. Weight loss with high and low carbohydrate $1200 \mathrm{kcal}$ diets in free living women. Eur J Clin Nutr 1997;51:243-8.

22 Anderson JW, Garrity TF, Wood CL, Whitis SE, Smith BM, Oeltgen PR. Prospective, randomized, controlled comparison of the effects of low-fat and low-fat plus high-fiber diets on serum lipid concentrations. Am J Clin Nutr 1992;56:887-94

23 Sarkkinen ES, Uusitupa MI, Pietinen P, Aro A, Ahola I, Penttila I, et al. Long-term effects of three fat-modified diets in hypercholesterolemic subjects. Atherosclerosis 1994;105:9-23

24 Dullaart RP, Beusekamp BJ, Meijer S, Hoogenberg K, van DJ, Sluiter WJ. Long-term effects of linoleic-acid-enriched diet on albuminuria and lipid levels in type 1 (insulin-dependent) diabetic patients with elevated urinary albumin excretion. Diabetologia 1992;35:165-72.

25 Rose GA, Thomson WB, Williams RT. Corn oil in treatment of ischaemi heart disease. $B M J 1965 ; 1: 1531-3$.

26 Ball KP, Hanington E, McAllen PM, Pilkington TRE, Richards JM, Sharland DE, et al. Low-fat diet in myocardial infarction: a controlled trial Lancet 1965;2:501-4.

27 Simon MS, Heilbrun LK, Boomer A, Kresge C, Depper J, Kim PN, et al. A randomized trial of a low-fat dietary intervention in women at high risk for breast cancer. Nutr Cancer 1997;27:136-42.

28 Boyd NF, McGuire V, Shannon P, Cousins M, Kriukov V, Mahoney L, et al Effect of a low-fat high-carbohydrate diet on symptoms of cyclical mastopathy. Lancet 1988;2:128-32.

29 Frantz ID Jr, Dawson EA, Ashman PL, Gatewood LC, Bartsch GE, Kub $\mathrm{K}$, et al. Test of effect of lipid lowering by diet on cardiovascular risk. The Minnesota coronary survey. Arteriosclerosis 1989:9:129-35.

30 Medical Research Council. Controlled trial of soya-bean oil in myocardial infarction. Lancet 1968;2:693-9.

31 van-het Hof $\mathrm{KH}$, Weststrate JA, van-den Berg $\mathrm{H}$, Velthuis-te Wierik EJ, de Graaf C, Zimmermanns NJ, et al. A long-term study on the effect of spontaneous consumption of reduced fat products as part of a normal diet on indicators of health. Int J Food Sci Nutr 1997:48:19-29.

32 National Diet Heart Study. Final report. Circulation 1968:37:1-428

33 Leren P. The effect of plasma cholesterol lowering diet in male survivor of myocardial infarction. A controlled clinical trial. Acta Med Scand Suppl 1966;466:1-92.

34 Hockaday TD, Hockaday JM, Mann JI, Turner RC. Prospective comparison of modified fat-high-carbohydrate with standard low-carbohydrate dietary advice in the treatment of diabetes: one year follow-up study. $\mathrm{BrJ}$ Nutr 1978;39:357-62.

35 Hellenius M-L, Krakau I, De Faire U. Favourable long-term effects from advice on diet and exercise given to healthy men with raised cardiovascular risks. Nutr Metab Cardiovasc Dis 1997;7:293-300.

36 Williams PT, Krauss RM, Stefanick ML, Vranizan KM, Wood PD. Effects of low-fat diet, calorie restriction, and running on lipoprotein subfraction concentrations in moderately overweight men. Metabolism 1994:43: 655-63. 
37 Watts GF, Lewis B, Brunt JN, Lewis ES, Coltart DJ, Smith LD, et al. Effects on coronary artery disease of lipid-lowering diet, or diet plu cholestyramine, in the St Thomas' atherosclerosis regression study (STARS). Lancet 1992;339:563-9.

38 Woodhill JM, Palmer AJ, Leelarthaepin B, McGilchrist C, Blacket RB. Low fat, low cholesterol diet in secondary prevention of coronary heart disease. Adv Exp Med Biol 1978;109:317-30.

39 McKeown-Eyssen GE, Bright SE, Bruce WR, Jazmaji V. A randomized trial of a low fat high fibre diet in the recurrence of colorectal polyps. Toronto polyp prevention group. J Clin Epidemiol 1994;47:525-36.

40 Marniemi J, Seppanen A, Hakala P. Long-term effects on lipid metabolism of weight reduction on lactovegetarian and mixed diet. Int J Obes 1990;14:113-25.

41 Dayton S, Pearce ML, Hashimoto S, Dixon WJ, Tomayasu U. A controlled clinical trial of a diet high in unsaturated fat in preventing complications of atherosclerosis. Circulation 1969;XL:II-1-63.

42 Black HS, Herd JA, Goldberg LH, Wolf-JE J, Thornby JI, Rosen T, et al. Effect of a low-fat diet on the incidence of actinic keratosis. $N$ Engl J Med 1994;330:1272-5.

43 Altman DG. Practical statistics for medical research. 1st ed. London: Chapman and Hall, 1991.
44 Hooper L, Ness A, Higgins JPT, Moore T, Ebrahim S. GISSI-Prevenzione trial [letter]. Lancet 1999;354:1557.

45 Randomised trial of cholesterol lowering in 4444 patients with coronary heart disease: the Scandinavian simvastatin survival study (4S). Lancet 1994;344:1383-9.

46 Davey Smith G, Song F, Sheldon TA. Cholesterol lowering and mortality: the importance of considering initial level of risk. BMJ 1993:306:1367-73.

47 Ebrahim S, Davey Smith G, McCabe C, Payne N, Pickin M, Sheldon TA, et al. Cholesterol and coronary artery disease: screening and treatment. Qual Health Care 1998;7:232-9.

48 Ebrahim S, Davey Smith G. Systematic review of randomised controlled trials of multiple risk factor interventions for preventing coronary heart disease. $B M J$ 1997;314:1666-74

49 De Lorgeril M, Renaud S, Mamelle N, Salen P, Martin JL, Monjaud I, et al. Mediterranean alpha-linolenic acid-rich diet in secondary prevention of coronary heart disease. Lancet 1994;343:1454-9.

50 Miettinen M, Turpeinen O, Karvonen MJ, Pekkarinen M, Paavilainen E, Elosuo R. Dietary prevention of coronary heart disease in women: the Finnish mental hospital study. Int J Epidemiol 1983;12:17-25.

(Accepted 16 January 2001)

\section{The effectiveness of exercise as an intervention in the management of depression: systematic review and meta-regression analysis of randomised controlled trials}

Debbie A Lawlor, Stephen W Hopker

\begin{abstract}
Objective To determine the effectiveness of exercise as an intervention in the management of depression. Design Systematic review and meta-regression analysis of randomised controlled trials obtained from five electronic databases (Medline, Embase, Sports Discus, PsycLIT, Cochrane Library) and through contact with experts in the field, bibliographic searches, and hand searches of recent copies of relevant journals.

Main outcome measures Standardised mean difference in effect size and weighted mean difference in Beck depression inventory score between exercise and no treatment and between exercise and cognitive therapy.

Results All of the 14 studies analysed had important methodological weaknesses; randomisation was adequately concealed in only three studies, intention to treat analysis was undertaken in only two, and assessment of outcome was blinded in only one. The participants in most studies were community volunteers, and diagnosis was determined by their score on the Beck depression inventory. When compared with no treatment, exercise reduced symptoms of depression (standardised mean difference in effect size -1.1 (95\% confidence interval -1.5 to -0.6 ); weighted mean difference in Beck depression inventory $-7.3(-10.0$ to -4.6$))$. The effect size was significantly greater in those trials with shorter follow up and in two trials reported only as conference abstracts. The effect of exercise was similar to that of cognitive therapy (standardised mean difference -0.3 (95\% confidence interval -0.7 to 0.1$)$ ). Conclusions The effectiveness of exercise in reducing symptoms of depression cannot be determined because of a lack of good quality research on clinical populations with adequate follow up.
\end{abstract}

\section{Introduction}

Depression is a common and important cause of morbidity and mortality worldwide. The effect of exercise on depression has been the subject of research for several decades, and the literature on the subject is growing. ${ }^{1}$ In the past decade "exercise on prescription" schemes have become popular in primary care in the United Kingdom, ${ }^{2}$ many of which include depression as a referral criterion.

Several plausible mechanisms for how exercise affects depression have been proposed. In the developed world taking regular exercise is seen as a virtue; the depressed patient who takes regular exercise may, as a result, get positive feedback from other people and an increased sense of self worth. Exercise may act as a diversion from negative thoughts, and the mastery of a new skill may be important. ${ }^{34}$ Social contact may be an important mechanism, and physical activity may have physiological effects such as changes in endorphin and monoamine concentrations. ${ }^{56}$

This review summarises the evidence from randomised controlled trials of the effectiveness of exercise as a treatment for depression.

\section{Methods}

\section{Identification of the studies}

We searched Medline (1966-99), Embase (1980-99), Sports Discus (1975-99), PsycLIT (1981-99), the Cochrane Controlled Trials Register, and the Cochrane Database of Systematic Reviews using the terms "exercise," "physical activity," "physical fitness," "walking," "jogging," "running," “cycling," “swimming," "depression," "depressive disorder," and "dysthymia." We also examined bibliographies, contacted experts, and hand searched copies published in the 12 months to December 1999 of selected journals (for details see the longer version of this paper on the BMJ's website).

\author{
Department of \\ Social Medicine \\ University of \\ Bristol, Bristol \\ BS8 2PR \\ Debbie A Lawlor \\ lecturer in \\ epidemiology and \\ public health medicine \\ Bradford \\ Community Trust, \\ Shipley, West \\ Yorkshire \\ BD18 3BP \\ Stephen W Hopker \\ consultant psychiatrist \\ Correspondence to: \\ D A Lawlor \\ D.A.Lawlor@bristol. \\ ac.uk
}

BMJ 2001;322:763-7

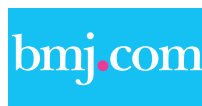

The full version of this paper appears on the BMJ's

website. This article is part of the BMJ's trial of open peer review, and documentation relating to this also appears on the website 